\title{
Improved Thermal Modelling and Experimental Validation of Oil-Flooded High Performance Machines with Slot-Channel Cooling
}

\author{
Fengyu Zhang, Member, David Gerada, Senior Member, Zeyuan Xu, Xiaochen Zhang, He Zhang, \\ Senior Member, Chris Gerada, Senior Member, Mingjun Zhu, Liqun Xia, Wei Zhang, Michele \\ Degano, Member
}

\begin{abstract}
Thermal management is often considered a bottleneck in the pursuit of the next generation electrical machines for electrified transportation with a step change in power density. Slot-channel cooling is considered to be an effective cooling technique, either as an independent method or as a secondary heat transfer path which compliments traditional cooling systems. The slotchannel specific geometry and position effects on the thermal benefits are not thoroughly investigated in literature, while previous work focuses on passing fluid through the un-used space left in between coils forming concentrated windings. In this paper, slot-channel cooling is implemented within an oil-flooded cooling system for a high power density motor used as a pump. A flexible and detailed lumped parameter thermal network (LPTN) is proposed for the cooling system, with the LPTN used to optimize the slot-channel dimensions and location for obtaining maximum thermal benefits. Finally, a surfacemount permanent magnet (SPM) machine with the optimized slot channel geometry is built and tested to validate the thermal model, experimentally achieving an armature continuous current density in excess of $30 \mathrm{~A} / \mathrm{mm}^{2}$.
\end{abstract}

Manuscript received March 28, 2021; revised July 4, 2021; accepted August 6, 2021. This work was supported in part by Ministry of Science \& Technology under National Key R\&D Program of China, under Grant 2021YFE0108600, in part by the Ningbo S\&T projects under Grant 2018B10002, and in part by the Key International Cooperation of National Natural Science Foundation of China under Grant 51920105011. (Corresponding author: David Gerada)

Fengyu Zhang, Zeyuan $\mathrm{Xu}$, and Michele Degano are with the Power Electronics, Machines and Control group, University of Nottingham, Nottingham, NG7 2RD, UK (email: Fengyu.Zhang1@nottingham.ac.uk; Zeyuan.Xu@nottingham.ac.uk; ezzmd2@exmail.nottingham.ac.uk).

David Gerada and Chris Gerada are with the Power Electronics, Machines and Control group, University of Nottingham, Nottingham, NG7 2RD,UK and also with the Key Laboratory of More Electric Aircraft Technology of Zhejiang Province, University of Nottingham Ningbo China, Ningbo 315100, China (email: David.Gerada@nottingham.ac.uk; Chris.Gerada@nottingham.ac.uk).

Xiaochen Zhang and He Zhang are with the Key Laboratory of More Electric Aircraft Technology of Zhejiang Province, University of Nottingham Ningbo China, Ningbo 315100, China (email: Xiaoch en.Zhang@nottingham.edu.cn; He.Zhang@nottingham.edu.cn)

Mingjun Zhu, Liqun Xia and Wei Zhang are with University of Nottingham Ningbo China, Ningbo 315100, China (email: woshizhu mingjun@126.com; xialiqun618fcd@163.com; zhangwei908@163.c om)
Index Terms-slot cooling, fully flooded oil cooling, thermal network, high speed, high power density, thermal management.

\section{I.INTRODUCTION}

$\mathrm{W}$ ith the increasingly stringent emission legislations, the world is developing moreelectric and all-electric transportation technologies at an unprecedented rate. High power density $(\mathrm{kW} / \mathrm{kg}$ or $\mathrm{kW} / \mathrm{L}$ ) electrical machines are at the heart of the electrified concepts [1]. The design of such electrical machines is a multi-domain challenge, which melds the electromagnetic aspect, the mechanical aspect as well as thermal management [2, 3].

Liquid cooling provides a more efficient cooling system for electrical machines with respect to natural convection, with the latter often resulting in bulky and heavier electrical machines [4]. Liquid cooling jacket is a mature liquid cooling method used reliably in many applications, where the heat generated within the machines is removed to the coolant located in a jacket surrounding the stator core-pack. The thermal performance can be furtherly improved with enhanced cooling techniques implemented in the end-winding region or the stator slot region, which play a critical role in determining the hot spot temperature of the electrical machines [4-6]. Potting the end-winding with high thermal conductivity materials [7, 8], and using higher thermal conductivity materials inside the slot, such as back-iron extension [9], are proven to shorten the heat transfer path between the windings and the coolant jacket and thus effectively reduce the peak temperature. Thermal techniques that combine the thermal improvements applied to both the end-winding as well as to the stator active parts are investigated in [10], where the end-winding is potted with a ceramicbased compound while copper bars are inserted in the stator tooth to further enhance indirect stator cooling.

Compared to traditional housing jacket cooling, direct cooling, whereby the fluid is in physical contact with the windings, is highly effective in removing heat and different approaches have been investigated. In [15], liquid coolant is injected into the stator to directly cool the windings, while a semi-flooded cooling 
system is proposed in [11] for a high speed application to limit the airgap losses. Spray cooling in the endwinding region [12, 13], and fully flooded cooling systems [4] are effective to cool machines with short stack length. Fully flooded cooling arrangements are commonly applied in the systems where the oil pump and drive motor are fully integrated. In such an arrangement the oil from the pumping system can be used to cool the machine [14]. In a fully flooded oil cooling system, the oil enters from one side of the machine unit, flows along the gap between the stator and the rotor, and finally leaves from the other side of the machine [4]. However, in some circumstances this intensive fully flooded cooling system is not sufficient to remove the massive heat generated by the windings in a high power density electrical machine, and thus combinations of different cooling techniques may be required.

Recently slot channel cooling, being direct cooling or indirect cooling, has been receiving increased attention [2, 15-20]. In such an arrangement the heat transfer path between the winding and the slot is significantly reduced, since the coolant is located in the slot and directly touches the windings. In [15], utilizing the space left between coils in a concentrated winding, a designed ' $\mathrm{T}$ ' shape slot channel is proposed to achieve a current density of $20.4 \mathrm{~A} / \mathrm{mm}^{2}$ while the hot spot temperature is $148^{\circ} \mathrm{C}$. Similarly, cooling channels derived from the unused space are proposed in [2]. However, the correlations between temperature and slot channel parameters, such as size and location remain uninvestigated, while they also play critical roles in the holistic process of electrical machine design. Meanwhile, the modelling technique for the aforementioned slot channel cooling thermal analysis presented in the existing literature is CFD, which is a very time demanding simulation approach $[15,21]$ and therefore not straightforward to be used within a multidomain optimization environment Computationally effective thermal model with CFD and Conjugate Heat Transfer (CHT) model implementation are investigated in [2, 22-25] for timeeffective thermal performance of the machine, where the copper loss increase with temperature is considered. Compared to CFD, lumped parameter thermal network (LPTN) is flexible and provides thermal results very quickly. Its accuracy can be furtherly improved with careful design and the temperature distribution can be obtained as well $[26$ 27].

In this paper, LPTN is used for the design and thermal analysis on a fully flooded oil cooling system (FFOCS) for a high power density electrical machine. After an initial thermal analysis, FFOCS alone is found not able to remove all the heat generated and allow the electrical machine to operate within the wire temperature limit $\left(210{ }^{\circ} \mathrm{C}\right)$. Slot channel cooling system (SCCS) is then proposed to be implemented together with the FFOCS. The slot cooling channel, including its geometry and location is optimized in a custom designed thermal model, used within a multidomain environment.

The main contributions of the paper are as follows:

- The combined cooling system of FFOCS and SCCS is investigated with thermal analysis and its effectiveness is experimentally validated. The presented cooling technique is applicable to high performance electrical machines.

- The slot channel geometry and location are optimized based on the balance between the increased copper losses due to reduced copper fill factor and the corresponding thermal benefits which have not been studied in previous literature. The methodology is applicable to various machine types, including those employing concentrated or distributed windings.

- The proposed and experimentally validated thermal modelling technique is a thermal approach to obtain accurate temperature distributions, including prediction of hot-spots, while benefitting from the LPTN's high computation speed.

- The proposed thermal modelling is accounting for novel cooling methodologies, i.e, slot channel cooling in this paper. With careful design, the developed thermal model can be extended to more complex geometries, such as those having multiple slot channels or irregular slot channel shape.

The structure of the paper is as follows: in section II, the designed SPM machine is presented, together with the proposed LPTN thermal model for the cooling system, which incorporates both the fully flooded oil cooling system (FFOCS) and the slot channel cooling system (SCCS). The slot cooling channel, including both its geometry and location in the slot is optimized in section III. In section IV, an SPM machine prototype with the optimized SCCS and FFOCS is built and tested to validate the thermal modelling of section III. Finally, conclusions from this research are summarized in Section V.

\section{II.THERMAL NETWORK FOR THE MACHINE}

In this section, the SPM machine is firstly introduced in Part A, with the losses calculation including copper and windage losses presented. A lumped parameter thermal network, considering both the SCCS and FFOCS is proposed and detailed in Part B.

\section{A. SPM machine introduction}

The requirement for the machine is: $9.6 \mathrm{~kW}$ at the rated speed of $8700 \mathrm{rpm}$, corresponding to a $10.6 \mathrm{Nm}$ rated torque. At the maximum speed of $19000 \mathrm{rpm}$ the corresponding torque is $5 \mathrm{Nm}$ [28]. The machine parameters are listed in TABLE 1, together with the 9slot, 8-pole permanent magnet prototype. SPM topology with a Halbach array and a hollow rotor shaft was selected for this application, taking into account the available converter $\mathrm{kVA}$, together with the 
gravimetric power density $(\mathrm{kW} / \mathrm{kg})$ and rotor inertia requirements. Other IPM motors with different rotor topologies could also be considered, however, to minimise the inertia of the rotor the advantages of an SPM Halbach and the very thin rotor back iron did represent the best choice for the case in hand.

TABLE 1. Electrical machine parameters summary

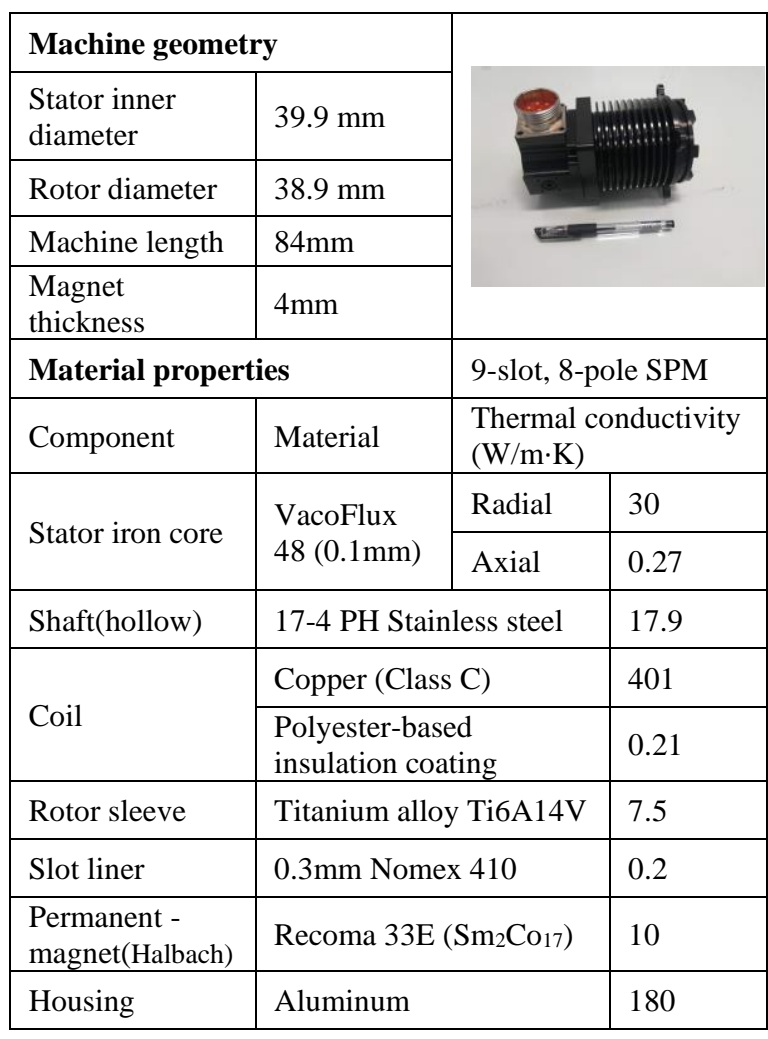

As this paper investigates the thermal performance of the SPM machine with SCCS and FFOCS, losses play a critical part in determining the thermal conditions of the electrical machine. The losses considered in this study are (i) winding losses in the stator slot, including DC and AC losses; (ii) windage losses due to the fully flooded cooling system and the high rotor speed; (iii) iron losses in both stator and rotor cores; and (iv) magnet losses.

As with most high power density machines, the majority of power losses are generated in the stator winding assembly, which consist of DC and AC losses [29]. AC losses are caused by skin-effect, proximity effects, circulating effects and slot leakage effects. Skin conductor effects are due to the current's tendency to flow on the periphery when the frequency increases, while proximity effects are due to the eddy currents caused by the changing magnetic flux produced by neighboring conductors. For high frequency electrical machines, AC resistance is significant and cannot be ignored [30]. The AC losses in equation (1) are calculated based on the ratio of AC resistance to DC resistance $k_{a c}$, using standard 3D FEA techniques, where the conductors within the slot are modeled at the strand level. From this analysis, $k_{a c}$ at the base speed of $8700 \mathrm{rpm}$ is 1.04 while at the maximum speed of $19000 \mathrm{rpm}$ it is 1.14. Copper DC electrical resistance $R_{d c}$ increases with temperature, with the rate described by the temperature coefficient of resistivity, $\alpha=0.003862$. Equation (2) is used for copper DC losses calculation $Q_{d c}$ with phase current $I$. In (2), $R_{p h 0}$ is the phase winding electrical resistance at the reference temperature $T_{0}$.

$$
\begin{gathered}
Q_{\text {total }}=Q_{d c}+Q_{a c}=k_{a c} \times Q_{d c} \\
Q_{d c}=3 I^{2} R_{p h 0}\left(1+\alpha\left(T_{a v e}-T_{0}\right)\right)
\end{gathered}
$$

Therefore, copper losses $Q_{\text {total }}$ calculation is linked with the winding temperature and cannot be determined at this stage. The copper losses will be presented together with the winding temperature derived from the thermal modelling at the end of section II.

Bertotti's formulation method is used within a 2D FEA model to compute iron losses directly $P_{F e}$, which are composed of three components: hysteresis, classical and excess loss, as described by formula (3) $[31,32]$. The stator iron losses are $208.7 \mathrm{~W}$ when the motor is operating at $8700 \mathrm{rpm}$.

$$
P_{F e}=k_{h} f B^{\alpha}+k_{e d d y} f^{2} B^{2}+k_{e x c} f^{1.5} B^{1.5}
$$

where $f$ and $B$ denote the frequency and magnetic flux density, respectively. Furthermore, $k_{h}, k_{e d d y}$, and $k_{\text {exc }}$ are the hysteresis, eddy current and excess loss coefficients, respectively. In this paper, for the electrical steel grade considered (VACOFLUX 480.1 $\mathrm{mm}), \quad k_{h}=0.007097, \quad k_{e d d y}=1.268 \times 10^{-6}$, and $k_{\text {exc }}=0.001735$, while $\alpha=5$.

Due to the friction effects caused by the relative motion between the rotor and the stator, windage loss is generated and contributes to the temperature rise in the electrical machine. Formula (4) is applied for windage loss calculation, where $C_{m}$ is the loss coefficient, $\omega$ is the rotor speed in $[\mathrm{rad} / \mathrm{s}], \rho$ is the fluid mass density in $\left[\mathrm{kg} / \mathrm{m}^{3}\right], l_{\text {ro }}$ is the rotor length in $[\mathrm{m}]$, $\mathrm{r}$ is the rotor radius in [m], $\delta$ is the airgap thickness in [m], and $v$ is the fluid (oil) kinematic viscosity in $\left[\mathrm{m}^{2} / \mathrm{s}\right]$ [33]. The oil's kinematic viscosity for an inlet temperature of $90{ }^{\circ} \mathrm{C}$ is $3.19 \times 10^{-6} \mathrm{~m}^{2} / \mathrm{s}$. The windage loss is $139 \mathrm{~W}$ at a rotor speed of $8700 \mathrm{rpm}$, half of which is applied to the stator while the other half is applied to the rotor [34].

$$
\begin{gathered}
P_{w}=0.5 C_{m} \rho \pi l_{r o} \mathrm{r}^{4} \omega^{3} \\
C_{m}=\mathrm{e}^{\gamma} / 1000 \\
T a=\frac{\omega r \delta}{v} \sqrt{\frac{\delta}{r}}
\end{gathered}
$$

when $T a \leq 400$ 


$$
\gamma=\ln (23)-0.351[\ln (T a)-\ln (10)]
$$

when $T a>400$

$$
\gamma=\ln (6.3)-0.141[\ln (T a)-\ln (400)
$$

\section{B. Thermal modelling}

For the SPM machine described in Part A, FFOCS is initially intended as the sole cooling technique, which is found as being not sufficient to remove all the heat generated within the machine. SCCS is then proposed to enhance the cooling the machine to operate within the temperature limit of the constituent materials. This part will present the thermal modelling for the electrical machine with both FFOCS and SCCS, which can also be intuitively modified to simulate the thermal performance of the machine with FFOCS only.

As can be seen from Fig. 1, the cooling system in the electrical machine consists mainly of two elements: (i) flooding oil in the end-winding region and in the airgap; (ii) forced oil convection in the slot cooling channel.

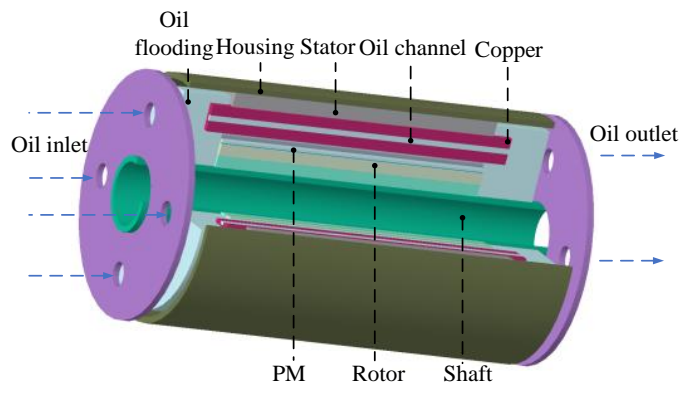

Fig. 1. 3D machine sketch with slot channel cooling

Considering heat transfer in both the radial and axial directions, a 3D LPTN with self-tuned number of nodes is built for the machine with SCCS and FFOCS, as shown in Fig. 2. The definition of 'self-tuned' here refers to the fact that the nodes' number for each part of the machine can be adjusted based on the thermal model accuracy and the computational efficiency requirements. The calculation time is ranging from seconds to few minutes with nodes number increasing to significant large values.

Exploiting the machine symmetries, half slot, and the corresponding rotor parts are simulated in the thermal network. In Fig. 2 (a), it can be seen that the half slot is divided into 5 regions: 'Region - I', 'Region - II', 'Region - III', 'Region - IV', and 'Region - V', where the widths of 'Region - I' and 'Region - V' are equal to the width of half the slot cooling channel, while the height of 'Region - III' is equal to that of the slot cooling channel. The number of nodes of 'Region - I' and 'Region - II' in the ' $y$ ' direction are independent, while they share the same number of nodes in the ' $x$ ' direction. Similarly, the nodes number of 'Region - IV' and 'Region - V' are the same in the ' $x$ ' direction while they can be different in the 'y' direction. The number of nodes of 'Region - II', 'Region - III' and 'Region - IV' regions are the same in the ' $y$ ' direction, while they are independent in the ' $\mathrm{x}$ ' direction. For the nodes' geometry determination, the maximum slot node width (and/or height) is set to $0.2 \mathrm{~mm}$ in this paper, which gives 1254 nodes in the half slot for one axial plane. The number of nodes in the ' $\mathrm{x}$ ' direction ' $N M_{x}$ ' is firstly determined using (9) for the aforementioned slot regions. ' $D S_{x}{ }^{\prime}$ is the maximum section length in the ' $x$ ' direction (mm). The mathematical symbol ' $\rceil{ }^{\prime}$ is used to indicate rounding up. The number of nodes in the ' $y$ ' direction are determined using a similar process.

$$
N M_{x}=\left\lceil\frac{D S_{x}}{(0.2)}\right\rceil
$$

Similarly, the stator tooth is divided into three regions as shown in Fig. 2(a): 'Tooth - I', 'Tooth - II' and 'Tooth - III', which share the same number of nodes in the ' $x$ ' direction with 'Region - II' 'Region III' and 'Region - IV' in the slot, respectively. There are three regions for stator back-iron. In the 'y' direction, 'Back-iron I', 'Back-iron - II' and 'Back-iron - III' share the same number of nodes with 'Region I', 'Region - II', and 'Tooth' regions, respectively.

For the sake of clarity, repetitive figures are avoided and only four sections are presented in the axial direction ('z' direction) in Fig. 2 (b), covering the three types of nodal connections: (i) between two endwinding sections, i.e., 'End-winding section a' and 'End-winding section b'; (ii) between stator core and end-region section, i.e., 'End-winding section b' and 'Core machine section c'; (iii) between stator core sections, i.e., 'Core machine d' and 'Core machine e'. In the thermal model, three end-winding sections for each end-winding region and eleven sections within the active length are selected to obtain time-efficient and accurate results. Fig. 2 (c) shows the nodes' connection to the flooding oil in the end-winding region, where all the windings are assumed to be extended from the slot and corresponding to 'Region - I' to 'Region - V'.

The thermal model for the machine without slot channel cooling system is derived from that with slot channel cooling, where the slot channel (i.e., 'rectangular blue region' in Fig. 2 (a) and the corresponding region in Fig. 2 (b) and (c) for both ' $x$ ' and ' $y$ ' directions) width and depth are set to infinitesimally small values.

Different nodes in Fig. 2 are linked with equation (10) for transient state calculation, where $c_{i}$ and $m_{i}$ are node $\mathrm{j}$ heat capacity and mass respectively, $T_{i}(\mathrm{t})$ and $T_{i}(\mathrm{t}-1)$ is the node $i$ temperature at time $\mathrm{t}$ and $\mathrm{t}-1$. $q_{i}(\mathrm{t}-1)$ is the heat generated within node $\mathrm{i}$ at time $\mathrm{t}-$ $1, T_{j}(\mathrm{t}-1)$ is node $\mathrm{j}$ temperature at time $\mathrm{t}-1, \Delta \mathrm{t}$ is the time step between iteration time $t$ and $\mathrm{t}-1$, which is $0.0001 \mathrm{~s}$ in this paper. $R_{i, j}$ is the thermal resistance between node $i$ and $\mathrm{j}$.

$$
\begin{gathered}
c_{i} m_{i}\left[T_{i}(\mathrm{t})-T_{i}(\mathrm{t}-1)\right]=\Delta \mathrm{t} \times q_{i}(\mathrm{t}-1)+ \\
\sum_{j \neq i} \frac{T_{j}(\mathrm{t}-1)-T_{i}(\mathrm{t}-1)}{R_{i, j}}
\end{gathered}
$$




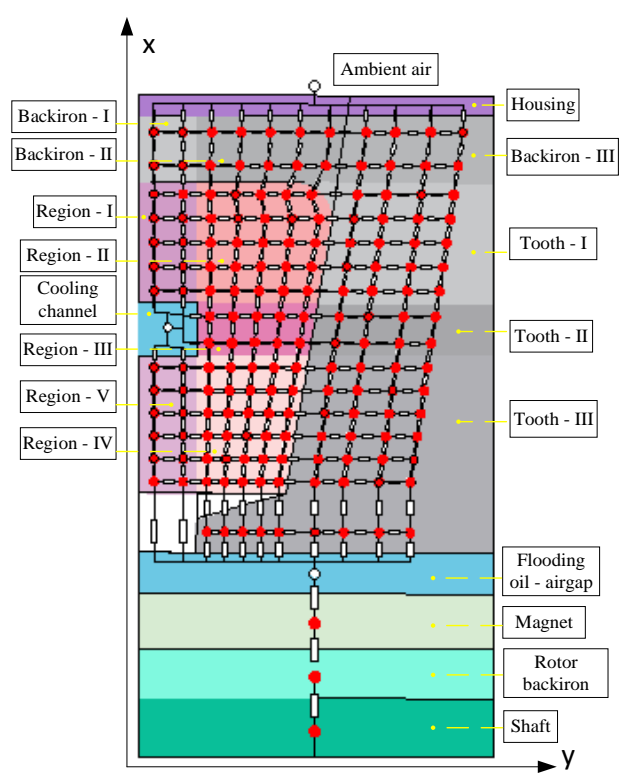

(a)

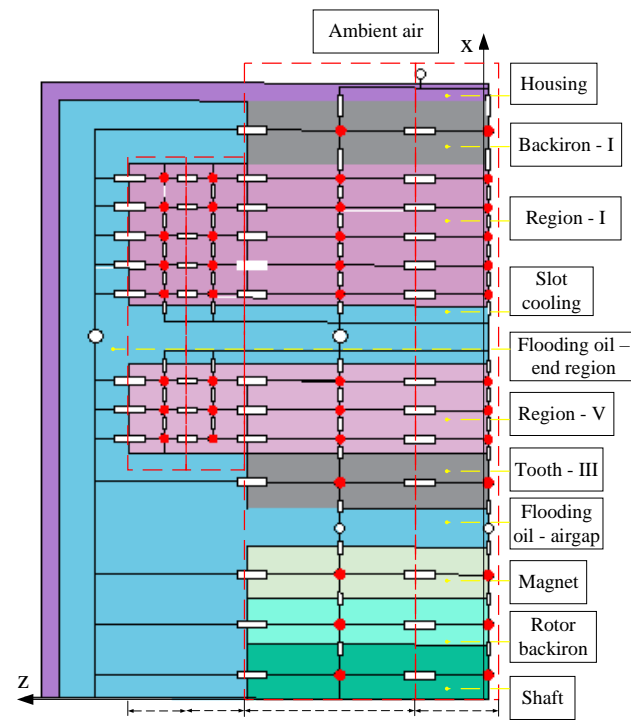

(b)

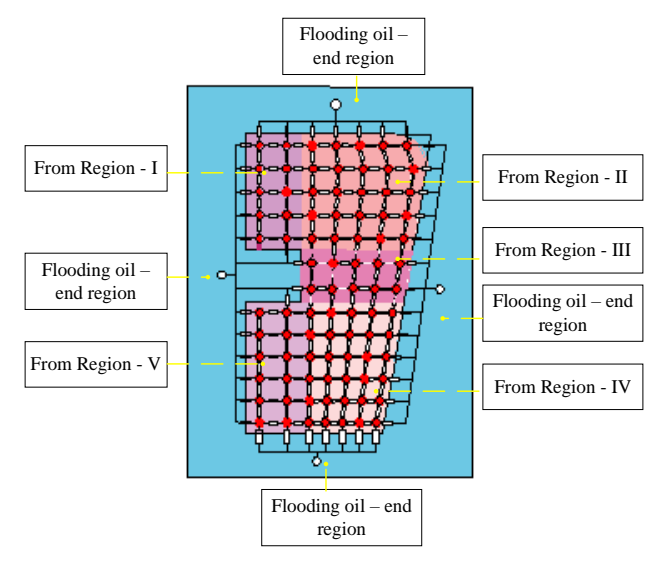

(c)

Fig. 2. 3D lumped parameter thermal network: (a) radial section, (b) axial section and (c) end-winding region
For $q_{i}$ in (10), the calculated losses in section II A, are evenly distributed into each node based on the volume. Copper losses are updated with temperature while other losses including iron losses are assumed constant. For wire node $\mathrm{i}$, the node loss $q_{i}(\mathrm{t})$ is calculated with formula (11), where $\alpha$ is a copper temperature coefficient, which is equal to 0.003862 . $q_{i}(0)$ is the heat generated within node $\mathrm{i}$ at reference temperature $T_{\text {ref }} 20^{\circ} \mathrm{C} . \mathrm{T}(\mathrm{i}, \mathrm{j})$ is node $\mathrm{j}$ temperature at time i.

$$
\frac{q_{i}(\mathrm{t})}{q_{i}(0)}=1+\alpha \times\left[T_{i}(\mathrm{t})-T_{r e f}\right]
$$

Equations (10) and (11) are used to compute the system transient state temperature, while for thermal steady state equation (12) is used.

$$
q_{i}+\sum_{j \neq i} \frac{T_{j}-T_{i}}{R_{m, j}}=0
$$

Resistances $R_{m, j}$ in equations from (10) to (12) consist of conduction, convection and radiation thermal resistances. These correspond to conduction, convection and radiation heat transfer, respectively. Radiation heat transfer is ignored in this paper as it is comparatively small compared to the other two types of heat transfer. Equation (13) is applied for the conduction thermal resistance calculation, where $l$ is the length in [m], $A_{\text {cond }}$ is the node cross-sectional area in $\left[\mathrm{m}^{2}\right]$, and $\lambda$ is the node thermal conductivity in $[\mathrm{W} /(\mathrm{m} \cdot \mathrm{K})]$ which is determined by the material properties.

$$
R_{\text {con }}=\frac{l}{\lambda A_{\text {cond }}}
$$

Equation (14) is used to calculate the convection heat transfer occurring in the following situations: (i) in the air-gap region; (ii) in the end-winding region; (iii) in the slot cooling channel. $A_{\text {conv }}$ is the contact area between the fluid and the solid, while the heat transfer coefficient $h$ is calculated using formulas from (15) to (24).

$$
R_{\text {conv }}=\frac{1}{h A_{\text {conv }}}
$$

In the case of convection heat transfer in the air-gap region [35, 36], with rotor speed of $8700 \mathrm{rpm}, h$ is obtained as $2562 \mathrm{~W} / \mathrm{m}^{2} \mathrm{~K}$ and Nusselt number $N u=13.17$ with formulas (15) to (18), where $\mathrm{D}_{a}$ is the equivalent diameter, $\delta$ is the air-gap thickness in [m], $v_{a}$ is the fluid axial flow velocity in $[\mathrm{m} / \mathrm{s}]$ calculated with the flowrate and the air-gap area, $v_{p}$ is the rotor peripheral velocity in $[\mathrm{m} / \mathrm{s}] ; \mathrm{v}_{\boldsymbol{e}}$ is the effective velocity in $[\mathrm{m} / \mathrm{s}] ; r_{s}, r_{r}$ are the stator inner radius and the rotor outer radius, $L$ is the motor length, and $v, \lambda$ and $P r$ are 
the oil's kinematic viscosity, thermal conductivity and Prandtl number, respectively.

$$
\begin{gathered}
h=\frac{N u \lambda}{\mathrm{D}_{a}} \\
\mathrm{D}_{a}=2 \delta, \mathrm{v}_{e}=\sqrt{\mathrm{v}_{a}^{2}+(1 / 4) \mathrm{v}_{p}^{2}} \\
N u=0.015\left(\frac{\mathrm{v}_{e} \mathrm{D}_{a}}{v}\right)^{0.8} \operatorname{Pr}^{\frac{1}{3}}(1 \\
\left.+2.3 \frac{\mathrm{D}_{a}}{L}\right)\left(\frac{r_{s}}{r_{r}}\right)^{0.45}
\end{gathered}
$$

In the end-winding region, particular attention should be paid to the Nusselt number $\mathrm{Nu}$ determination [29]. Different formulas are used to calculate $\mathrm{Nu}$ corresponding to different parts in the end-winding region $[37,38]$ : near the stator, near the stator winding, near the rotor. Equation (18) is applied to the heat transfer between the stator and the flooding oil, while equations (21) and (22) are applied for the convection heat transfer between the rotor/floodingoil, and between the end-winding surfaces/floodingoil. The Reynolds and Nusselt numbers vary based on different calculation points and are difficult to be determined directly. In this section, firstly the heat transfer coefficient values are calculated using (23), while the fluid is assumed as air [39], with $k_{1}=15$, $k_{2}=0.4, k_{3}=0.9$. Then the heat transfer values are derived with the ratio of oil thermal conductivity to that of air, and the ratio of oil Prandtl number to that of air, respectively. The heat transfer coefficients obtained at $8700 \mathrm{rpm}$ are 1559 in $\left[\mathrm{W} / \mathrm{m}^{2} \mathrm{~K}\right], 2682$ in $\left[\mathrm{W} / \mathrm{m}^{2} \mathrm{~K}\right]$, and 5207 in $\left[\mathrm{W} / \mathrm{m}^{2} \mathrm{~K}\right]$, corresponding to the convection regions between stator/flooding-oil, end-winding surfaces/flooding-oil, and rotor/flooding-oil, respectively.

$$
\begin{gathered}
N u=0.664 \operatorname{Re}^{0.5} \operatorname{Pr}^{0.33} \\
N u=0.153 \operatorname{Re}^{0.618} \operatorname{Pr}^{0.33} \\
N u=0.076 \operatorname{Re}^{0.7} \operatorname{Pr}^{0.36} \\
h=k_{1}\left(1+k_{2} \text { vel }^{k_{3}}\right)
\end{gathered}
$$

where $k_{1}, k_{2}, k_{3}$ are the curve fit coefficients, while vel is the rotor peripheral velocity.

For the slot cooling channel, formulas (22) to (24), are used to calculate the heat transfer coefficient [40], where $\lambda, \mu$ and $V$ are the oil's thermal conductivity in $[\mathrm{W} /(\mathrm{m} \cdot \mathrm{K})]$, dynamic viscosity in $[\mathrm{kg} /(\mathrm{m} \mathrm{s})]$ and the oil velocity in $[\mathrm{m} / \mathrm{s}]$, respectively. $V$ is calculated with flowrate and the slot channel area. The parameter $D_{h}$ is the hydraulic diameter of the slot cooling channel in [m]. Re and $P r$ denote Reynolds number and Prandtl number, while $S$ and $P$ are the slot cooling channel area and peripheral length, respectively. $L$ is the machine stack length and $\alpha$ is the slot cooling channel's height to width ratio.

$$
\begin{gathered}
h=\lambda N u / D_{h} \\
R e=\rho V D_{h} / \mu, D_{h}=4 S / P \\
N u=7.49-17.02 \alpha+22.43 \alpha^{2}- \\
9.94 \alpha^{3}++\frac{0.065 \times\left(D_{h} / L\right) \operatorname{RePr}}{1+0.04 \times\left(\left(D_{h} / L\right) \operatorname{RePr}\right)^{2 / 3}}
\end{gathered}
$$

The heat transfer coefficients in the air-gap and in the end-winding region are mainly dependent on the rotor speed, and less sensitive to the oil flow rate. The convection heat transfer in the slot cooling channel, however, is changing with the oil flow rate, with the variation plotted in Fig. 3, for a fixed slot channel geometry and location in the slot at the rated speed of 8700rpm.

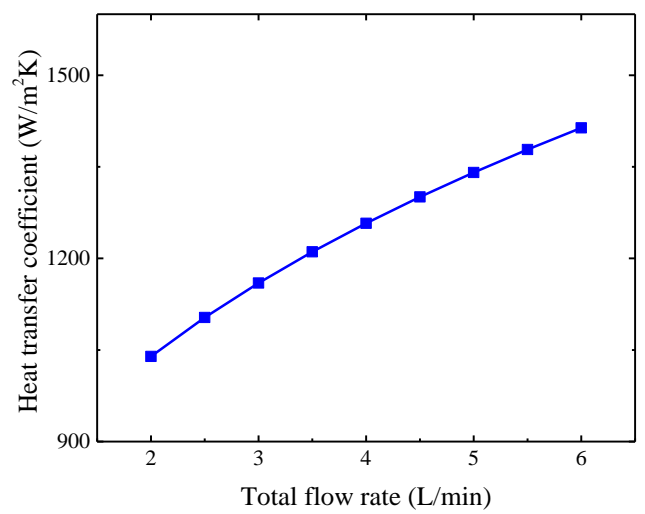

Fig. 3. Heat transfer coefficient variations with cooling fluid flow rate

With the presented thermal model, at the rated power and speed, considering an oil inlet temperature of $90^{\circ} \mathrm{C}$, the theoretical highest temperature for the machine with FFOCS (fully flooding oil cooling system) only is $269^{\circ} \mathrm{C}$. The total copper loss obtained is $1109 \mathrm{~W}$. It can be deduced that the FFOCS alone is not sufficient to cool the machine below the wire thermal limit of $210^{\circ} \mathrm{C}$, for which thermal limit the maximum continuous current density achieved is $22.1 \mathrm{~A} / \mathrm{mm}^{2}$.

Slot channel cooling system is therefore incorporated with the fully flooded oil cooling system in this paper in order to help dissipate the heat generated within the machine, especially in the slot, to the flooding oil. However, the cooling channel occupies space inside the slot which would otherwise be available for the copper and thus for a given reference temperature increases the resistance of the winding. From the foregoing discussion, the slot channel geometry is an important element that needs to be carefully investigated to achieve the maximum thermal benefits. 


\section{III.THERMAL IMPROVEMENT WITH SLOT CHANNEL COOLING}

In this section, based on the thermal modelling proposed in section II, the slot cooling channel geometry and its location within the slot are investigated for the maximum thermal benefits.

Three main variables are used to describe the shape and position of the slot channel geometry as shown in Fig. 4, namely, (i) slot channel width; (ii) slot channel depth; (iii) slot channel location. Subsection A investigates the slot channel width and depth (i.e., (i) and (ii)) effects on the peak temperature of the machine, while subsection B focuses on the cooling channel location. The three variables are scanned within defined ranges as detailed in the following subsections to provide a clear picture of the temperature tendency.

\section{A. Slot channel width and depth sensitivity analysis on temperature}

For a comprehensive view of the slot channel geometry effects on winding temperature and manufacturing flexibility consideration, the selected slot cooling channel (SCC) width dimensions are discrete values, starting from $1 \mathrm{~mm}$ and increasing at a step size change of $1 \mathrm{~mm}$, up to a maximum width of $4 \mathrm{~mm}$ (corresponding to $\sim 62 \%$ of the top slot width), as listed in TABLE 2, and described in Fig. 4. On the other hand, finer resolution is considered for the slot cooling channel (SCC) depth which varies from 0.5 $\mathrm{mm}$ to $4.9 \mathrm{~mm}$ ( $60 \%$ of the winding depth), with a step change of $0.4 \mathrm{~mm}$. In the first analysis, only the SCC width and depth are varying, while the SCC center is fixed at the middle point of the slot (i.e, the slot channel center location ' $H$ ' $=4.25 \mathrm{~mm}$ in Fig. 4).

TABLE 2. Investigated slot cooling channel geometries

\begin{tabular}{|c|c|c|c|}
\hline Simulation & $\begin{array}{l}\text { SCC } \\
\text { width }\end{array}$ & SCC depth & $\begin{array}{l}\text { SCC } \\
\text { location }\end{array}$ \\
\hline SCC - i & $1 \mathrm{~mm}$ & \multirow{4}{*}{$\begin{array}{c}0.5-4.9 \\
\mathrm{~mm}, \text { in steps } \\
\text { of } 0.4 \mathrm{~mm}\end{array}$} & \multirow{4}{*}{$\begin{array}{c}H^{\prime}= \\
4.25 \mathrm{~mm}\end{array}$} \\
\hline SCC - ii & $2 \mathrm{~mm}$ & & \\
\hline SCC - iii & $3 \mathrm{~mm}$ & & \\
\hline SCC - iv & $4 \mathrm{~mm}$ & & \\
\hline
\end{tabular}

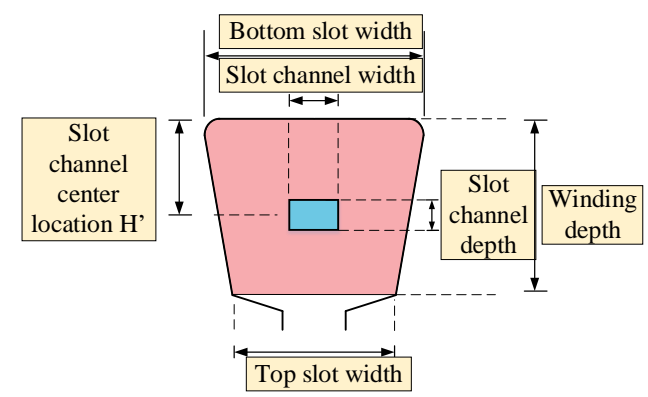

Fig. 4. Slot geometry and cooling channel parameters
The copper fill factor, defined as the ratio of copper area to the slot area, is firstly studied and plotted in Fig. 5. It can be seen that the copper fill factor decreases linearly with SCC depth for all the four SCC widths considered from the original value 0.47 , due to the fact that the slot cooling channel occupies space which would otherwise be available for winding. The smaller the copper fill factor is, the higher the copper losses are for a given current and winding temperature. In practice, the copper losses are updated with SCC geometries to the developed 3D thermal modelling in section II. Using formulas (2) and (11), it can be seen that the losses vary since the channel affects the coil temperature and its resistance. In this case, the copper losses are affected by two factors: (i) the winding temperature; (ii) the increased electrical resistance due to reduced copper fill factor in Fig. 5. The copper losses taking into account the temperature effects are plotted in Fig. 6.

In Fig. 7, the peak temperature is plotted for all the combinations listed in TABLE 2. As mentioned earlier on in section II, the original motor temperature is $269^{\circ} \mathrm{C}$ without the slot cooling channel. The original temperature is now plotted in Fig. 7 for a clear view of the temperature trends when considering slot channel cooling.

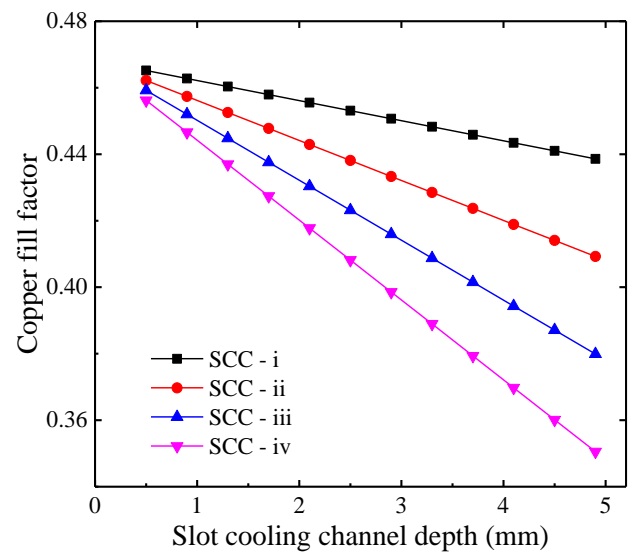

Fig. 5. Copper fill factor variation with slot cooling channel geometry

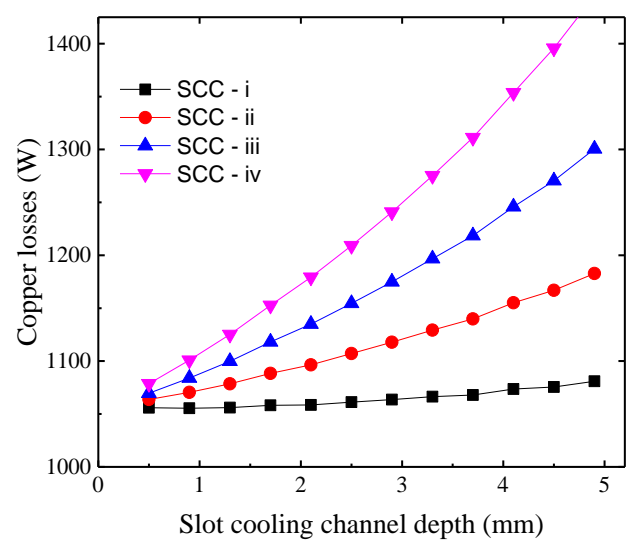

Fig. 6. Copper losses variation with slot cooling channel geometry, considering the thermal effects 
It can be seen from Fig. 7 that all the proposed slot cooling channels provide temperature reductions compared to the original motor. The temperature is decreasing throughout the studied SCC depths for 'SCC - i', which is the narrowest channel considered, $1 \mathrm{~mm}$ wide. For ' $\mathrm{SCC}-\mathrm{i}$ ' the cooling benefits with the slot channel outweigh the increased copper losses due to the reduced copper fill factor. The significant temperature reduction achieved is also the main reason that the copper losses for ' $\mathrm{SCC}-\mathrm{i}$ ' are lower than those for the original motor (1109W from section II B), as shown in Fig. 6, even with lower copper fill factor.

For wider slot cooling channels ('SCC - ii', 'SCC iii' and ' $\mathrm{SCC}$ - iv'), the peak temperature tendency is to decrease first and then increase due to the higher copper losses coming from the reduced copper fill factor.

As shown in Fig. 7, both SCC widths of $3 \mathrm{~mm}$ and $4 \mathrm{~mm}$ provide promising thermal benefits with $2 \mathrm{~mm}$ SCC depths. Further increase in SCC depth doesn't guarantee significant temperature reduction, reduces the flexibility of slot channel location optimization, while complicating the manufacturing process.

Therefore, for further slot channel location improvement, two types of slot channel geometries are selected: (i) slot channel ' $A$ ' with $3 \mathrm{~mm}$ SCC width and $2 \mathrm{~mm}$ SCC depth. (ii) slot channel ' $B$ ' with $4 \mathrm{~mm}$ SCC width and $2 \mathrm{~mm}$ SCC depth.

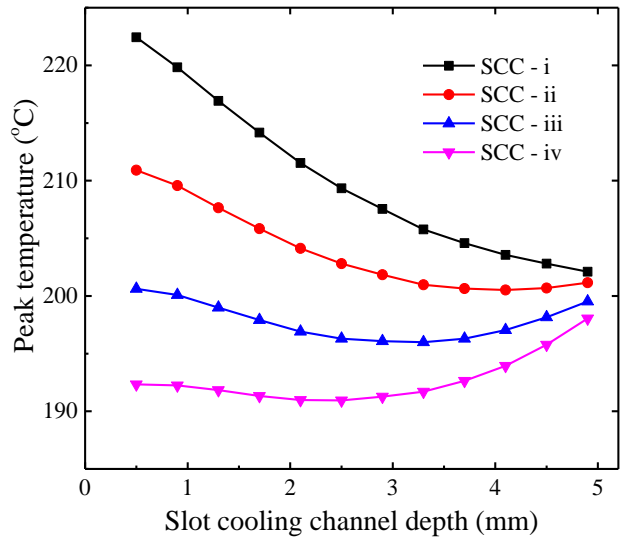

Fig. 7. Peak temperature variation with slot cooling channel geometry

\section{B. Slot channel location analysis}

In this section, the two selected slot channel types ' $A$ ' (i.e., slot channel width $3 \mathrm{~mm}$ and depth $2 \mathrm{~mm}$ ) and 'B' (i.e., slot channel width $4 \mathrm{~mm}$ and depth $2 \mathrm{~mm}$ ) are compared, while the center of the slot channel location ' $H$ ' in Fig. 4, is varying from $2.25 \mathrm{~mm}$ to $5.25 \mathrm{~mm}$ for both channel types. Of note when the slot channel center is at the center of the slot, ${ }^{\prime} H^{\prime}=4.25 \mathrm{~mm}$.

It can be seen from Fig. 8 that the temperature drops and then increases with the value of ' $H$ ', while the optimized location for slot channel $\mathrm{A}$ is ${ }^{\prime} H^{\prime}=3.6 \mathrm{~mm}$ and it is ' $H^{\prime}=3.7 \mathrm{~mm}$ for slot channel B. With the optimized slot channel location, the temperature for slot channel A is $191{ }^{\circ} \mathrm{C}$, while it is $184^{\circ} \mathrm{C}$ for slot channel B.

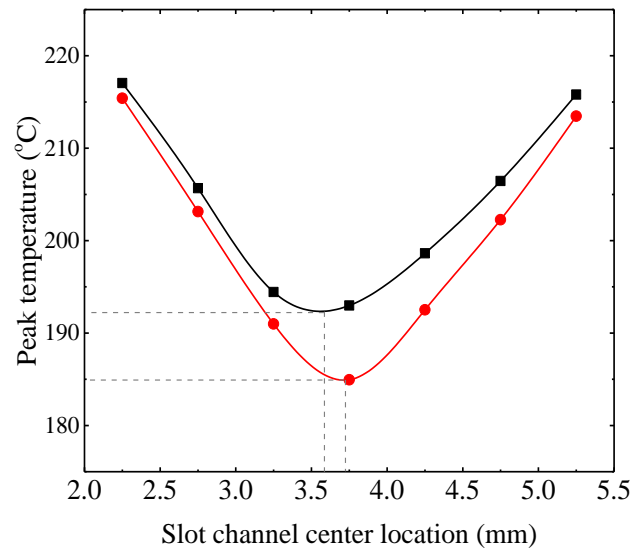

- Slot channel A, 3mm SCC width, $2 \mathrm{~mm}$ SCC depth - Slot channel B, 4mm SCC width, $2 \mathrm{~mm}$ SCC depth

Fig. 8. Peak temperature variation with slot channel location

For a clear view of the temperature distribution in the slot, the temperature contour is plotted in Fig. 9, for slot channel A located at $2.25 \mathrm{~mm}, 3.25 \mathrm{~mm}$ and 5.25 $\mathrm{mm}$. When the slot channel A center is at $2.25 \mathrm{~mm}\left({ }^{\prime} H^{\prime}\right.$ $=2.25 \mathrm{~mm}$ ), the hot spot is near the slot opening, as shown in Fig. 9 (a). This is because significant thermal barriers are resulted due to low thermal conductivity wedge placed in between the winding and the flooding oil. Conversely, the hot spot is pushed to the corner of the slot, near the back-iron and the tooth, when the slot channel is near the slot opening, as shown in the case of Fig. 9 (c).

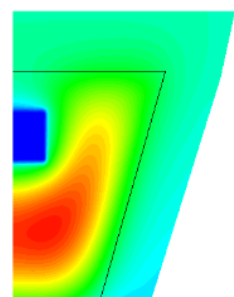

(a)

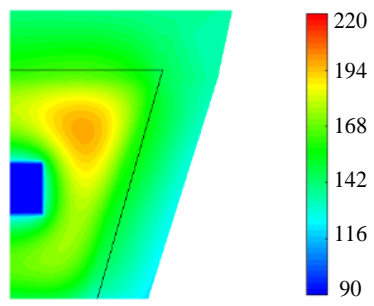

(b)

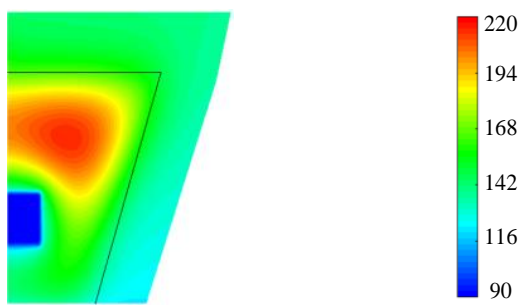

(c)

Fig. 9. Slot temperature contour for machine with slot cooling channel A (a) ${ }^{\prime} H^{\prime}=2.25 \mathrm{~mm}$ (b) ${ }^{\prime} H^{\prime}=3.6 \mathrm{~mm}$ (c) ${ }^{\prime} H^{\prime}=5.25 \mathrm{~mm}$

In this paper, considering the manufacturing feasibility, slot channel A with $3 \mathrm{~mm}$ width and $2 \mathrm{~mm}$ depth is selected to be applied with the flooding oil 
cooling system. The slot channel center location ' $H^{\prime}=$ $3.6 \mathrm{~mm}$, is selected as being the optimal for minimizing the coil temperature as shown in Fig. 8.

\section{Thermal results}

With the optimized slot channel A dimensions ( $3 \mathrm{~mm}$ SCC width, 2mm SCC depth) updated into the thermal model, Fig. 10 is obtained for the $26.84 \mathrm{~A} / \mathrm{mm}^{2}$ current density. As can be observed from Fig. 10(b), the temperature is reduced largely with the slot channel cooling system, with respect to the original machine of Fig. 10 (a). Meanwhile, with the channel, the hot spot moves from the center of the slot to the corner of the slot bottom.

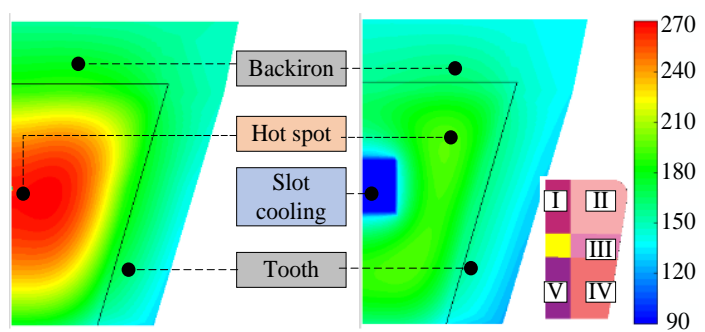

(a)

(b)

Fig. 10. Temperature contour (a) Machine with only oil flooding system (b) Machine with both oil flooding and slot channel cooling system

Fig. 11 presents the temperature distribution in the axial direction, for the different slot regions described earlier in Section II. It can be clearly seen that with the proposed thermal management the peak temperature occurs within the core part in 'Region - II', which concurs well with Fig. 10

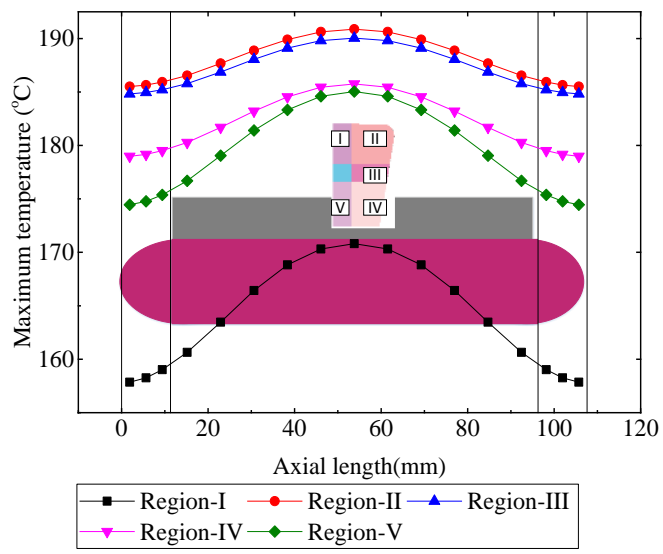

Fig. 11. Axial temperature distribution

\section{D.Generalization aspect}

The previous sub-sections presented the thermal benefits with the optimized slot channel geometry and location. To derive the relationship between the machine dimensions and the slot cooling channel geometry for best thermal performance, different motors with scaling ratio of 0.5 to 5 are studied. In this exercise, the slot channel width is selected as being $50 \%$ of the slot top width ' $\mathrm{w}_{2}$ ' for manufacturing reasons, as shown in Fig. 12, while the slot channel depth is varying from $10 \%$ to $80 \%$ of the winding depth. It is found out that, the slot channel depth for best thermal benefits is $40 \%$ - $60 \%$ of the winding depth. With fixed slot channel width as $0.5 \mathrm{w}_{2}$ and the slot channel depth as $0.5 \mathrm{~h}_{\mathrm{w}}$, the optimized slot channel center location is around $0.4 \mathrm{~h}_{\mathrm{w}}$, slightly above the slot center towards the slot bottom. However, for a specific machine design, mechanical restrictions should also be taken into consideration during the slot cooling channel optimization process.

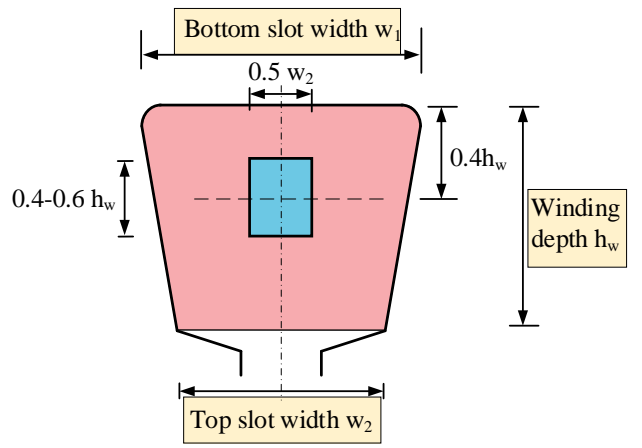

Fig. 12. Optimized slot channel geometry

\section{IV.EXPERIMENTAL RESULTS}

An SPM machine prototype with the proposed slot channel geometry is built and tested in this section. Firstly, a dummy stator with windings is used to test the slot channel feasibility, followed by the manufacturing and testing on a full motor. Finally, the experimental measurements are presented and compared with simulation results for validation.

\section{A. Dummy stator manufactured}

A plastic stator with the same geometry of the SPM machine designed, with dimensions reported in TABLE 1 , is firstly 3D printed and wound as shown in Fig. 13(a) for an early feasibility trial study on the slot fill factor. Similar to other novel cooling concepts implemented in prototypes [41], the slot cooling channels require the development of a careful manufacturing procedure. One possible way for the implementation is to use 'cooling-channel-formers' which capture the dimensional and positional properties of the designed cooling channels. The formers are used during the winding process and removed post stator impregnation. For this it is important to carefully choose the material properties of the resin and the former, in a way that the resin does not attach to the former, hence easing the procedure for the removal of the former post impregnation. 


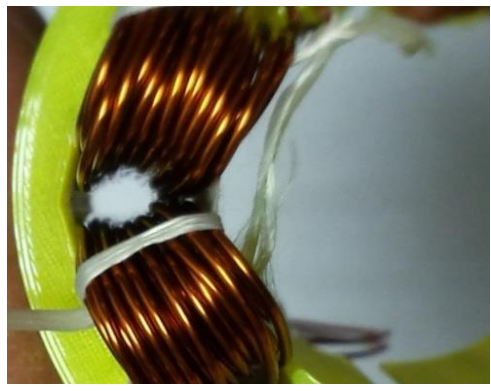

(a)

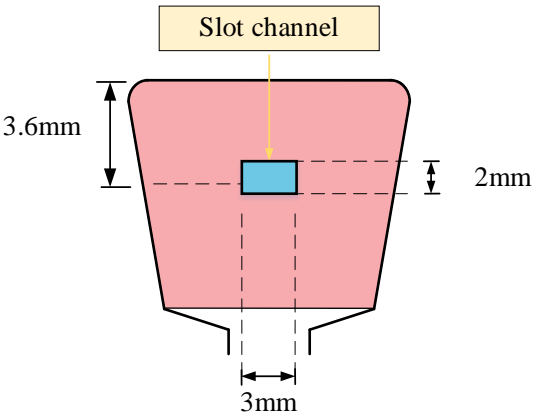

(b)

Fig. 13. Slot winding trial

\section{B. Experimental test rig}

The high power density SPM machine is prototyped and tested with the materials and geometry summarized in TABLE 1. Air release valves are installed on the machine housing to release any air trapped in the machine to ensure the machine is fully flooded. Peak temperature reduction is the main focus of this work, which limits the maximum current (and corresponding power) of the machine. Multiple K-type thermocouples are placed within the stator slots in the stator core as well as in the end-windings to extract the hot spot temperatures and validate the thermal model. The K-type thermocouples are calibrated by placing them in the same thermally insulated segment at room temperature and the variation is within $0.1^{\circ} \mathrm{C}$ between different thermocouples. The physical locations ' $\mathrm{A}$ ' and ' $\mathrm{B}$ ' of thermocouple placement are described in Fig. 14(a). As mentioned in section II-B, and illustrated within Fig. 14 (b) there are three end-winding sections for each end-region and eleven sections within the active length. TABLE 3 summarizes the thermocouple locations used within the experimental campaign. Both transient and steady state temperatures are recorded and compared to the analysis.

In Fig. 15, the prototype is installed on a test bench to validate the design and proposed thermal modelling of section II as well as thermal results of section III. Fig. 15(a) shows the test rig flow loop, including cooling unit (Tool temp 188), 10 micron oil filter, pressure transmitters at the inlet and outlet of the motor, and temperature measurement devices (Pico logger). The oil used in this research is Eastman Turbo
Oil 2389 and the overall flow rate is $4 \mathrm{~L} / \mathrm{min}$, which is the same cooling medium condition as in the application where the drive motor is fully integrated with an oil pump. The oil is pre-heated to guarantee an inlet temperature of $90^{\circ} \mathrm{C}$, with the lab ambient temperature being $30^{\circ} \mathrm{C}$.

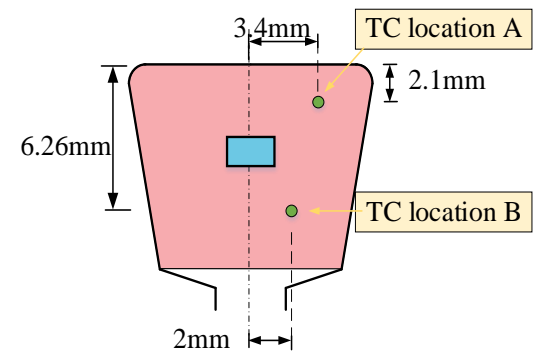

(a)

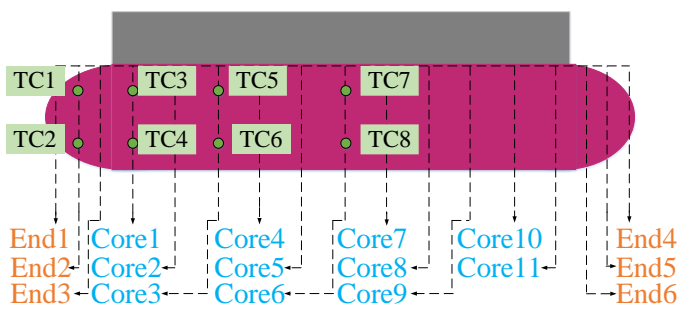

(b)

Fig. 14. Thermocouple locations: (a) in the slot; (b) in the axial sections

TABLE 3. Thermocouple locations

\begin{tabular}{|l|l|l|}
\hline \multirow{2}{*}{ Thermocouples } & \multicolumn{2}{|l|}{ Location } \\
\cline { 2 - 2 } & In the slot & $\begin{array}{l}\text { In axial } \\
\text { direction }\end{array}$ \\
\hline TC1 & Location A & \multirow{2}{*}{ End1 } \\
\hline TC2 & Location B & \\
\hline TC3 & Location A & \multirow{2}{*}{ Core1 } \\
\hline TC4 & Location B & \\
\hline TC5 & Location A & \multirow{2}{*}{ Core3 } \\
\hline TC6 & Location B & \\
\hline TC7 & Location A & \multirow{2}{*}{ Core6 } \\
\hline TC8 & Location B & \\
\hline
\end{tabular}

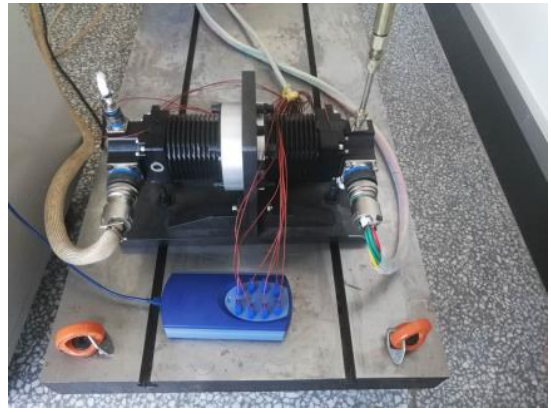

(b)

Fig. 15. Experimental set-up: a) flow loop with auxiliary elements; b) machine under test close-up view 


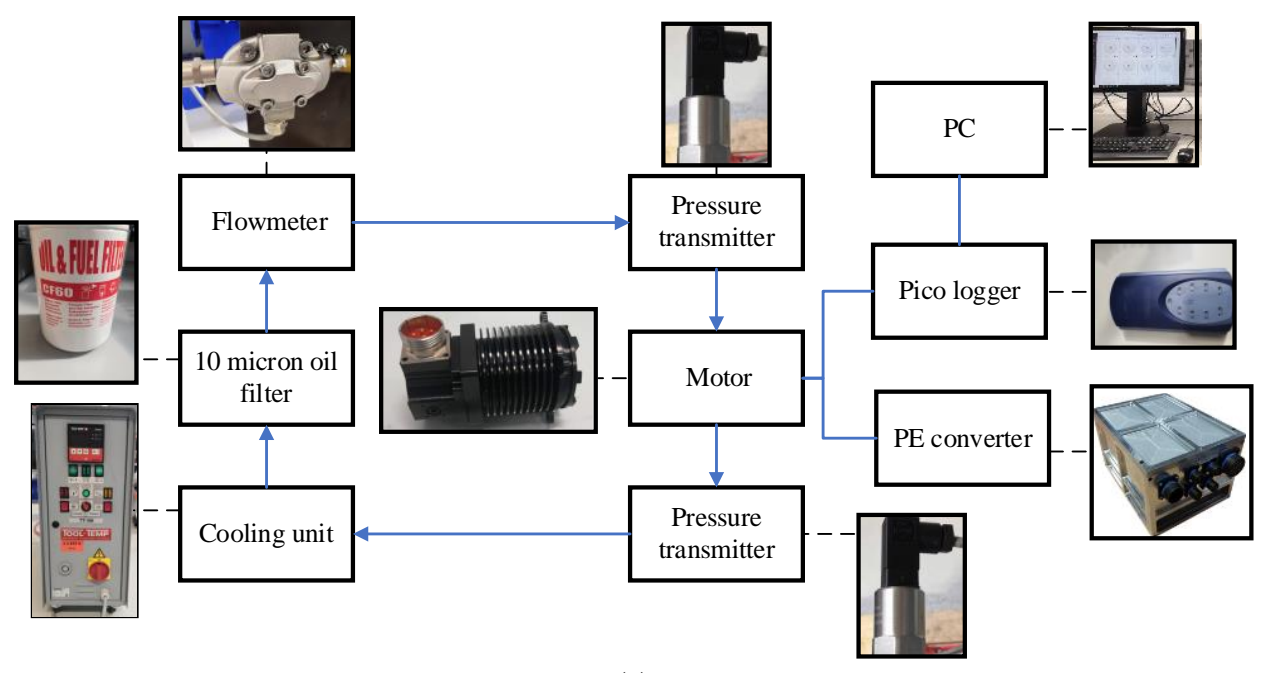

(a)

Fig.15 Experimental set-up: a) flow loop with auxiliary elements; b) machine under test close-up view

\section{C.Experimental results}

The SPM machine runs at rated power and speed, $9.6 \mathrm{~kW}$ 8700rpm for 900 seconds during which the thermal steady state is reached after approximately 300 seconds, as can be seen from Fig. 16, where the simulation and experimental results are plotted and compared for TC1 and TC7. In Fig. 16, the solid lines $(-)$ represent the experimental results while the simulation results are represented with dashed lines (--). The system pressure drop extracted from the pressure transmitters installed at the inlet and outlet of the machine is $22.5 \mathrm{kPa}$.

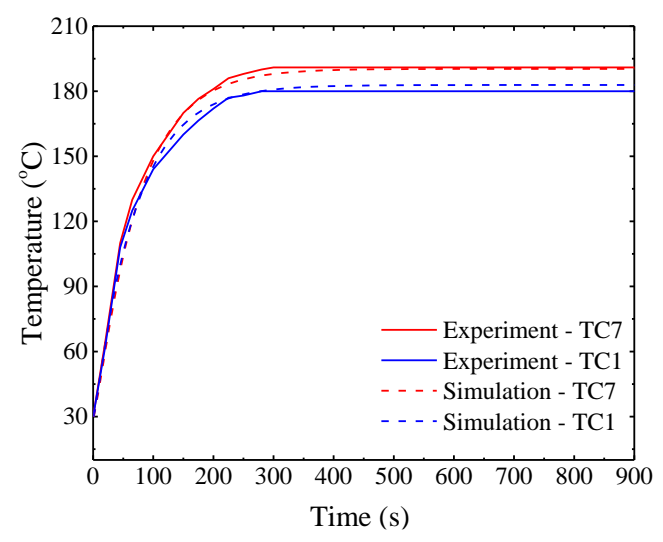

Fig. 16. Transient temperature comparison between simulation and experimental results

The maximum temperature of $191^{\circ} \mathrm{C}$ (TC7) is recorded in the axial middle section of the core, while it is $183.32^{\circ} \mathrm{C}$ (TC1) in the end-winding region, as shown in Fig. 16 and TABLE 4. The experimental data matches well with the peak temperature in the simulation results, with the predicted temperatures to within 3\% compared to the experimental results, as shown in TABLE 4 . The axial temperature profile as predicted by the described LPTN also shows good agreement to the experimentally measured one as shown in Fig. 17. Importantly, with slot channel cooling added to the flooding oil cooling system, the temperature is reduced significantly from $269^{\circ} \mathrm{C}$ to $191{ }^{\circ} \mathrm{C}$ (about $28.9 \%$ ), and a continuous current density of $26.84 \mathrm{~A} / \mathrm{mm}^{2}$ can be sustained. The continuous current density can be increased to be $30 \mathrm{~A} / \mathrm{mm}^{2}$ $(+11.77 \%)$ before reaching the wire thermal limit of $210^{\circ} \mathrm{C}$.

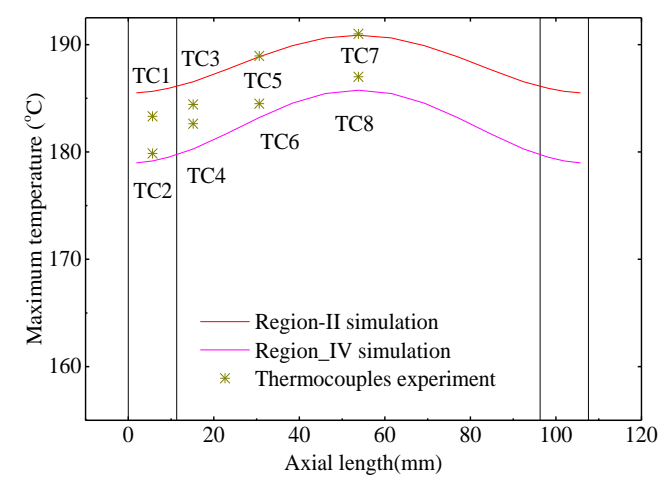

Fig. 17. Steady temperature comparison between simulation and experimental results along the machine axial length

TABLE 4. Steady temperature comparison

\begin{tabular}{|l|c|c|}
\hline TCs & Experiment $\left({ }^{\circ} \mathrm{C}\right)$ & Simulation $\left({ }^{\circ} \mathrm{C}\right)$ \\
\hline TC1 & 183.32 & $185.65(2.5 \%)$ \\
\hline TC2 & 179.86 & $179.17(-0.8 \%)$ \\
\hline TC3 & 184.43 & $186.53(2.2 \%)$ \\
\hline TC4 & 182.63 & $180.27(2.54 \%)$ \\
\hline TC5 & 188.94 & $188.88(-0.06 \%)$ \\
\hline TC6 & 184.5 & $183.21(-1.4 \%)$ \\
\hline TC7 & 191 & $190.88(-0.1 \%)$ \\
\hline TC8 & 187 & $185.75(-1.3 \%)$ \\
\hline
\end{tabular}




\section{V.CONCLUSION}

Improved thermal management targeting the coil area and associated copper losses is critical for the next generation e-machines with a step change in power density. Slot channel cooling is considered to be a promising cooling technique in the thermal management of electrical machines. In this paper, firstly the thermal performance of the slot channel cooling system combined with fully flooded oil cooling system for a SPM machine is investigated with a bespoke designed thermal network, which captures the slot channel geometry variation. The slot channel geometry along with its location in the slot are optimized for the maximum thermal benefits. Finally, an SPM machine prototype is built and tested based on the optimized slot cooling channel. The experimental results are in overall good agreement with the simulation results. With the combined cooling system, the prototype can generate the required output torque with a high current density $\left(26.84 \mathrm{~A} / \mathrm{mm}^{2}\right)$ successfully sustained continuously, while the current density can be furtherly increased to beyond $30 \mathrm{~A} / \mathrm{mm}^{2}$ to work within the wire thermal limit $\left(210{ }^{\circ} \mathrm{C}\right)$, compared to $22.1 \mathrm{~A} / \mathrm{mm}^{2}$ with only fully flooded oil cooling system. For a comprehensive view, the maximum current density that can be achieved for more common wire type of $180^{\circ} \mathrm{C}$ thermal limit is $25.38 \mathrm{~A} / \mathrm{mm}^{2}$. From a manufacturing perspective, the proposed cooling technique which combines fully flooded oil cooling and slot channel oil cooling can be carefully embedded in high power density electrical machines, for both concentrated windings or distributed windings, with the help of spacers specially designed for the winding process and proper sealing mechanisms. In such cooling system, where the air-gap is oil flooded, mechanical losses such as friction losses generated within the air-gap will reduce the machine efficiency. At the rated speed of 8700rpm, the windage losses are $139 \mathrm{~W}$ or $8.6 \%$ of the total losses, with the corresponding efficiency of the machine being $85.7 \%$. The suitable cooling medium for such system is desired to have high thermal conductivity, high electrical resistivity and low viscosity. Other properties such as compatibility with insulation and oxidation stability should also be considered for this kind of application.

\section{REFERENCES}

[1] A. Al-Timimy, G. Vakil, M. Degano, P. Giangrande, C. Gerada, and M. Galea, "Considerations on the Effects That Core Material Machining Has on an Electrical Machine's Performance," IEEE Transactions on Energy Conversion, Article vol. 33, no. 3, pp. 1154-1163, 2018, Art no. 8295137, doi: 10.1109/TEC.2018.2808041.

[2] A. Acquaviva, S. Skoog, and T. Thiringer, "Design and Verification of In-slot Oil-Cooled Tooth Coil Winding PM Machine for Traction Application," IEEE Transactions on Industrial Electronics, 2020.

[3] D. Golovanov, L. Papini, D. Gerada, Z. Xu, and C. Gerada, "Multidomain Optimization of High-Power-Density PM Electrical Machines for System Architecture Selection," IEEE
Transactions on Industrial Electronics, vol. 65, no. 7, pp. 53025312, 2018.

[4] P. Ponomarev, M. Polikarpova, and J. Pyrhönen, "Thermal modeling of directly-oil-cooled permanent magnet synchronous machine," in 2012 XXth International Conference on Electrical Machines, 2-5 Sept. 2012 2012, pp. 1882-1887, doi: 10.1109/ICElMach.2012.6350138.

[5] F. Zhang, D. Gerada, Z. Xu, H. Zhang, and C. Gerada, "Sensitivity analysis of machine components thermal properties effects on winding temperature," in 2019 22nd International Conference on Electrical Machines and Systems (ICEMS), 2019: IEEE, pp. 1-5.

[6] Z. F et al., "Slot Number Thermal Effects on Electrical Machines," IEEE Transactions on Energy Conversion, pp. 1-1, 2020, doi: 10.1109/TEC.2020.3008219.

[7] Y. Yao, L. Gu, T. Fan, W. Sun, and J. Luo, "Evaluation of heat transfer characteristic of Aluminum Nitride (AlN) potting compound for the end windings of permanent magnet synchronous machines," in 2011 International Conference on Electrical and Control Engineering, 2011: IEEE, pp. 44984501.

[8] S. Nategh, D. Barber, A. Boglietti, D. Lindberg, O. Aglen, and R. Brammer, "A study on thermal effects of different potting strategies in traction motors," in 2018 IEEE International Conference on Electrical Systems for Aircraft, Railway, Ship Propulsion and Road Vehicles \& International Transportation Electrification Conference (ESARS-ITEC), 2018: IEEE, pp. 16.

[9] F. Zhang et al., "Back-Iron Extension Thermal Benefits for Electrical Machines With Concentrated Windings," IEEE Transactions on Industrial Electronics, vol. 67, no. 3, pp. 17281738, 2020, doi: 10.1109/TIE.2019.2903758

[10] J. Pyrhönen, P. Lindh, M. Polikarpova, E. Kurvinen, and V. Naumanen, "Heat-transfer improvements in an axial-flux permanent-magnet synchronous machine," Applied Thermal Engineering, vol. 76, pp. 245-251, 2015.

[11] Z. Xu et al., "A semi-flooded cooling for a high speed machine: Concept, design and practice of an oil sleeve," in IECON 2017 43rd Annual Conference of the IEEE Industrial Electronics Society, 2017: IEEE, pp. 8557-8562.

[12] T. Davin, J. Pellé, S. Harmand, and R. Yu, "Experimental study of oil cooling systems for electric motors," Applied Thermal Engineering, vol. 75, pp. 1-13, 2015.

[13] C. Liu et al., "Experimental Investigation on Oil Spray Cooling with Hairpin Windings," IEEE Transactions on Industrial Electronics, pp. 1-1, 2019, doi: 10.1109/TIE.2019.2942563.

[14] Z. Xu et al., "Thermal management of a permanent magnet motor for an directly coupled pump," in 2016 XXII International Conference on Electrical Machines (ICEM), 4-7 Sept. 2016 2016, pp. 2738-2744, doi: 10.1109/ICELMACH.2016.7732909.

[15] W. Sixel, M. Liu, G. Nellis, and B. Sarlioglu, "Cooling of Windings in Electric Machines via 3D Printed Heat Exchanger," IEEE Transactions on Industry Applications, pp. 1-1, 2020, doi: 10.1109/TIA.2020.2997902.

[16] P. Lindh et al., "Direct liquid cooling method verified with an axial-flux permanent-magnet traction machine prototype," IEEE Transactions on Industrial Electronics, vol. 64, no. 8, pp. 6086-6095, 2017.

[17] M. Schiefer and M. Doppelbauer, "Indirect slot cooling for high-power-density machines with concentrated winding," in 2015 IEEE International Electric Machines \& Drives Conference (IEMDC), 10-13 May 2015 2015, pp. 1820-1825, doi: 10.1109/IEMDC.2015.7409311.

[18] S. A. Semidey and J. R. Mayor, "Experimentation of an Electric Machine Technology Demonstrator Incorporating Direct Winding Heat Exchangers," IEEE Trans. Industrial Electronics, vol. 61 , no. 10 , pp. 5771-5778, 2014.

[19] Z. Liu, T. Winter, and M. Schier, "Direct coil cooling of a high performance switched reluctance machine (SRM) for EV/HEV applications," SAE International Journal of Alternative Powertrains, vol. 4, no. 1, pp. 162-169, 2015.

[20] P. M. Lindh et al., "Direct liquid cooling in low-power electrical machines: Proof-of-concept," IEEE transactions on energy conversion, vol. 31, no. 4, pp. 1257-1266, 2016. 
[21] R. Camilleri, D. A. Howey, and M. D. McCulloch, "Predicting the temperature and flow distribution in a direct oil-cooled electrical machine with segmented stator," IEEE Transactions on Industrial Electronics, vol. 63, no. 1, pp. 82-91, 2015.

[22] L. Boscaglia, A. Boglietti, S. Nategh, F. Bonsanto, and C. Scema, "Numerically-based Reduced-order Thermal Modeling of Traction Motors," IEEE Transactions on Industry Applications, pp. 1-1, 2021, doi: 10.1109/TIA.2021.3077553.

[23] L. Boscaglia, F. Bonsanto, A. Boglietti, S. Nategh, and C. Scema, "Conjugate Heat Transfer and CFD Modeling of Selfventilated Traction Motors," in 2019 IEEE Energy Conversion Congress and Exposition (ECCE), 29 Sept.-3 Oct. 2019 2019, pp. 3103-3109, doi: 10.1109/ECCE.2019.8913138.

[24] A. Walter-Krause, "Application of Conjugate Heat Transfer Simulations for the Development of Ventilation and Cooling Systems for Large Hydro Generators," in 2018 XIII International Conference on Electrical Machines (ICEM), 3-6 Sept. 2018 2018, pp. 2633-2639, doi: 10.1109/ICELMACH.2018.8507248.

[25] A. Acquaviva, O. Wallmark, E. A. Grunditz, S. T. Lundmark, and $\mathrm{T}$. Thiringer, "Computationally efficient modeling of electrical machines with cooling jacket," IEEE Transactions on Transportation Electrification, vol. 5, no. 3, pp. 618-629, 2019.

[26] S. Nategh, Z. Huang, A. Krings, O. Wallmark, and M. Leksell, "Thermal modeling of directly cooled electric machines using lumped parameter and limited CFD analysis," IEEE Transactions on Energy Conversion, vol. 28, no. 4, pp. 979-990, 2013.

[27] M. Bouheraoua, M. Atig, and R. Khaldi, "Thermal investigation of Three-Phase Induction Motors with an Integrated Open-Phase Fault Operation Using a Lumped Parameter Thermal Network (LPTN)," in 2019 19th International Symposium on Electromagnetic Fields in Mechatronics, Electrical and Electronic Engineering (ISEF), 29-31 Aug. 2019 2019, pp. 1-2, doi 10.1109/ISEF45929.2019.9097102.

[28] A. Al-Timimy et al., "Design and losses analysis of a high power density machine for flooded pump applications," IEEE Transactions on Industry Applications, vol. 54, no. 4, pp. 32603270,2018

[29] B. Bilgin et al., "Modeling and Analysis of Electric Motors: State-of-the-Art Review," IEEE Transactions on Transportation Electrification, vol. 5, no. 3, pp. 602-617, 2019 , doi: 10.1109/TTE.2019.2931123.

[30] A. Bardalai et al., "Reduction of Winding AC Losses by Accurate Conductor Placement in High Frequency Electrical Machines," IEEE Transactions on Industry Applications, vol. 56, no. 1, pp. 183-193, 2020, doi: 10.1109/TIA.2019.2947552.

[31] G. Bertotti, "General properties of power losses in soft ferromagnetic materials," IEEE Transactions on magnetics, vol 24, no. 1, pp. 621-630, 1988.

[32] D. M. Ionel, M. Popescu, M. I. McGilp, T. Miller, S. J. Dellinger, and R. J. Heideman, "Computation of core losses in electrical machines using improved models for laminated steel," IEEE Transactions on Industry Applications, vol. 43, no. 6, pp. 1554-1564, 2007.

[33] D. Staton, "Motor-CAD V2," Motor Design Ltd, 2005

[34] J. Chin, S. Hwang, H. Park, and J. Hong, "Thermal Analysis and Verification of PMSM Using LPTN Considering Mechanical Components and Losses," in 2018 XIII International Conference on Electrical Machines (ICEM), 3-6 Sept. 2018 2018, pp. 1323-1329, doi: 10.1109/ICELMACH.2018.8507164.

[35] M. Fénot, Y. Bertin, E. Dorignac, and G. Lalizel, "A review of heat transfer between concentric rotating cylinders with or without axial flow," International journal of thermal sciences. vol. 50, no. 7, pp. 1138-1155, 2011.

[36] F. Tachibana and S. Fukui, "Convective heat transfer of the rotational and axial flow between two concentric cylinders," Bulletin of JSME, vol. 7, no. 26, pp. 385-391, 1964.

[37] J. Montonen, J. Nerg, M. Polikarpova, and J. Pyrhönen, "Integration Principles and Thermal Analysis of an Oil-Cooled and -Lubricated Permanent Magnet Motor Planetary Gearbox Drive System," IEEE Access, vol. 7, pp. 69108-69118, 2019 , doi: 10.1109/ACCESS.2019.2919506.
[38] F. P. Incropera, "Fundamentals of Heat and Mass Transfer," ed: John Wiley \& Sons, Inc., 2006.

[39] D. Staton, A. Boglietti, and A. Cavagnino, "Solving the more difficult aspects of electric motor thermal analysis in small and medium size industrial induction motors," IEEE Transactions on Energy Conversion, vol. 20, no. 3, pp. 620-628, 2005.

[40] V. Gnielinski, "New equations for heat and mass transfer in turbulent pipe and channel flow," Int. Chem. Eng., vol. 16, no. 2, pp. 359-368, 1976.

[41] A. Acquaviva, S. Skoog, and T. Thiringer, "Manufacturing of tooth coil winding PM machines with in-slot oil cooling," in 2020 International Conference on Electrical Machines (ICEM), 2020, vol. 1: IEEE, pp. 2314-2320.

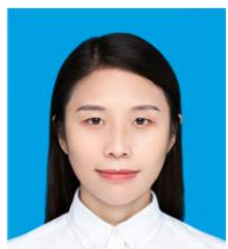

Fengyu Zhang (Member, IEEE) received B.E degree in thermal engineering from Huazhong University of Science and Technology, Wuhan, China in 2014 and $\mathrm{Ph} . \mathrm{D}$. degree in electrical machines from University of Nottingham in 2019

She is currently a Research Fellow in the area of thermal management on electrical machines within the PEMC group at University of Nottingham. Her main research interests include high performance motors for transport applications and their multi-domain optimization.

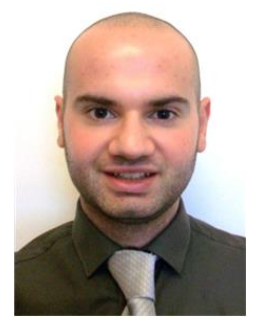

David Gerada (Senior Member, IEEE) received the Ph.D. degree in high-speed electrical machines from University of Nottingham, Nottingham, U.K., in 2012.

From 2007 to 2016, he was with the R\&D Department at Cummins, Stamford, U.K., first as an Electromagnetic Design Engineer (2007- 2012), and then as a Senior Electromagnetic Design Engineer and Innovation Leader (2012- 2016). At Cummins, he pioneered the design and development of high-speed electrical machines, transforming a challenging technology into a reliable one suitable for the transportation market, while establishing industry-wide-used metrics for such machinery. In 2016, he joined the University of Nottingham where he is currently a Principal Research Fellow, responsible for developing state-of-the-art electrical machines for future transportation which push existing technology boundaries, while propelling the new technologies to higher technology readiness levels.

Dr. Gerada is a Chartered Engineer in the U.K. and a member of the Institution of Engineering and Technology.

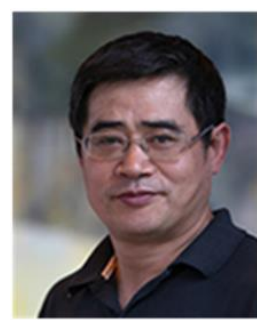

Zeyuan Xu received the Ph.D. degree in mechanical engineering from the University of Manchester, Manchester, U.K., in 2002.

He subsequently worked as a Research Fellow at UMIST, Brunel University, and University of Nottingham. He is currently a Senior Research Fellow in thermomechanical design of high speed electrical machines within the PEMC group at University of Nottingham, Nottingham, U.K. His main research interests include turbulent thermo-fluid flow, heat transfer enhancement, and thermal management of advanced electrical machines and power electronics. 


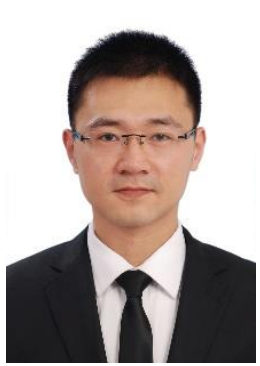

Xiaochen Zhang (Member, IEEE) graduated from Harbin University of Science and Technology and received Master's Degree in 2006. He graduated from Harbin Institute of Electrical Technology and received Doctor's Degree in 2012.

$\mathrm{He}$ is with the Department of Electric and Electronic Engineering, University of Nottingham Ningbo China. His research interests include research on electromagnetic and thermal analysis on electrical machine, especially in permanent magnetic machines and high speed machines.

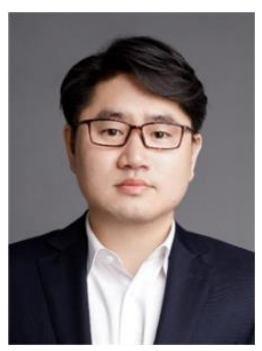

He Zhang (Senior Member, IEEE) received his B.Eng. degree from Zhejiang University, China, in 2002. He obtained the MSc. and Ph.D. degree in electrical machines from The University of Nottingham, UK, in 2004 and 2009 respectively.

He worked as Research Fellow at the University and Director of BestMotion Technology Centre, Nottingham, UK. He moved to University of Nottingham Ningbo China as Senior Research Fellow in 2014, promoted to Principal Research Fellow in 2016 and to Professor in 2020.He is currently the Director of Nottingham Electrification Centre (NEC) within the Power electronics, Machines and Control research group in University of Nottingham Ningbo China. His research interests include high performance electric machines and drives for transport electrification.

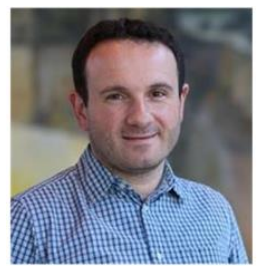

Chris Gerada (Senior Member, IEEE) received the $\mathrm{Ph} . \mathrm{D}$. degree in numerical modelling of electrical machines from the University of Nottingham, Nottingham, U.K., in 2005.

$\mathrm{He}$ worked as a Researcher with the University of Nottingham, on highperformance electrical drives and the design and modeling of electromagnetic actuators for aerospace applications. In 2008, he was appointed as a Lecturer of Electrical Machines, in 2011, as an Associate Professor, and in 2013, as a Professor with the University of Nottingham. He is currently an Associate Pro-Vice-Chancellor of Industrial Strategy and Impact and a Professor of Electrical Machines with the University of Nottingham, UK. He has secured over $£ 20 \mathrm{M}$ of funding through major industrial, European, and U.K. grants and authored more than 350 referred publications. His principal research interest lies in electromagnetic energy conversion in electrical machines and drives, focusing mainly on transport electrification.

Prof. Gerada was awarded a Research Chair from the Royal Academy of Engineering in 2013. He served as an Associate Editor for the IEEE TRANSACTIONS ON INDUSTRY APPLICATIONS and is the past Chair of the IEEE IES Electrical Machines Committee.

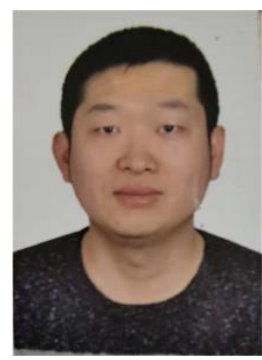

Mingiun Zhu received B.E degree in electrical engineering from Northwestern Polytechnical University, Xi'an, China, in 2011 and Master degree in electrical engineering from Harbin Institute of Technology, Harbin, China, in 2013. Currently he is visiting scholar with University of Nottingham Ningbo China.

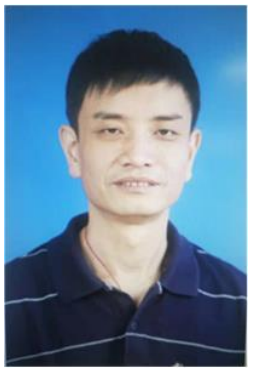

Liqun Xia received Ph.D. degree in navigation guidance and control from Northwestern Polytechnical University, Xi'an, China, in 2009. Currently he is visiting scholar with University of Nottingham Ningbo China.

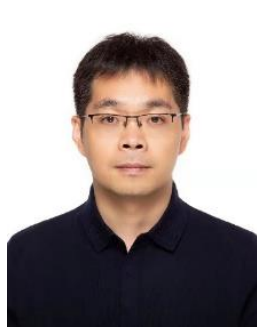

Wei Zhang received Ph.D. degree in automation engineering from Northwestern Polytechnical University, Xi'an, China in 2009. Currently he is visiting scholar with University of Nottingham Ningbo China.

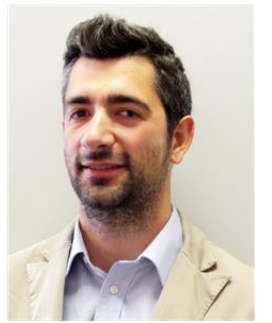

Michele Degano (Member, IEEE) received his Master's degree in Electrical Engineering from the University of Trieste, Italy, in 2011, and his Ph.D. degree in Industrial Engineering from the University of Padova, Italy, in 2015. Between 2014 and 2016, he was a post-doctoral researcher at The University of Nottingham, UK, where he joined the Power Electronics, Machines and Control (PEMC) Research Group. In 2016 he was appointed Assistant Professor in Advanced Electrical Machines, at The University of Nottingham, UK. He was promoted Associate Professor in 2020. Dr. Degano is currently the PEMC Director of Industrial Liaison leading research projects for the development of future hybrid electric aerospace platforms and electric transports. He is author/co-author of more than 100 scientific papers and an Associate Editor of the IEEE Transactions on Energy Conversion. His main research focuses on electrical machines and drives for industrial, automotive, railway and aerospace applications, ranging from small to large power. 